\title{
The Brief Enlightenment of the One Belt and One Road to the Reform of Private Universities at Chongqing
}

\author{
Ruosi Chen
}

City College of Science and Technology, Chongqing University, Chongqing 402167, China

\begin{abstract}
The "One belt and One road", that means "the Silk Road Economic Belt and the 21st-Century Maritime Silk Road". From The "One Belt and One Road" was raised on September and October 2013 in China, it created more opportunities of integration about economy and culture from China to Central Asia and Europe.Chongqing is the center of the west regions in China. From June 18, 1997 Chongqing has became the municipality directly under the central government, it has driven the southwest regions to develop very well. In 2018, Chongqing realized GDP of 2036.319 billion Yuan, kept 6\% GDP growth rates. At Chongqing, the proportion of private-public universities is 2:3, there are 26 privates colleges and universities. More and more young people will graduate from the privates universities, under the background of "One Belt and One Road",it's necessary to raise some suggestion about the reform of privates universities at Chongqing.

Keywords: One Belt and One Road; Reform of Private University; Yu'Xin'Ou Railway
\end{abstract}

COPYRIGHT

Copyright (C) 2019 by author(s) and Frontier Scientific Publishing. This work is licensed under the Creative Commons

Attribution-NonCommercial 4.0

International License (CC BY-NC 4.0). http://creativecommons.org/licenses/

\section{The situation and development of "One Belt and One Road" in Chongqing}

\subsection{Introduction}

As the pioneer of "One Belt And One Road", by the end of 2017, the cumulative number of trains of $\mathrm{Yu}^{\prime} \mathrm{Xin}$ 'Ou Railway ( 渝 新 欧 ) exceeded 1500.Yu'Xin'Ou Railway (渝新欧) is a international railway line which has gone into operation in 2011 from Chongqing to the Europe with the great support of National Ministries and Commissions such as the General Administration of Customs and the Ministry of Railways. It begins at the only municipality of the Midwest of China, passes Gansu province, Xinjiang province and arrives china's frontier Alashankou port, enters Kazakhstan, Russia, Belarus and Poland, finally arrives Duisburg of Germany covering about 11,000 kilometers. In 2012, this railway line prolonged from Duisburg of Germany to Anvers of Belgium. Thence Chongqing and EU's headquarter Belgium have been connected by this railway. It's a further optimization of the original Eurasian Land Bridge. Name Yu'Xin'Ou one 渝 新 欧 is an acronym, consisting of “Yu” 渝 (Chongqing), “Xin” 新 (Xinjiang),“Ou” 欧 Europe. Chongqing,Moscow,Duisburg and Astana are 4 important stations of Yu'Xin'Ou Railway (渝新欧).

The data showed that By the end of August 2018, Yu'Xin'Ou Railway has a total 1442 classes trains (outward 714 classes and return 728 classes),it's the first time that the number of return classes was more than the number of outward classes, the actual load rate was more than $90 \%$. According to Chongqing customs statistics, in the first half of 2019, the total value of imports and exports of Chongqing was 266.36 billion yuan, up $16.48 \%$ year-on-year; the imports and exports to the EU amounted to 50.52 billion yuan, up 21.9\% YOY. 


\subsection{The situation and development of $\mathrm{Yu}^{\prime} \mathrm{Xin}$ 'Ou Railway}

From these years' performance of Yu'Xin'Ou Railway, not only it should gain a firm foothold in Europe,but also it will face the intratype-competition with other China-Europe train. It should be based on Chongqing's resource, develop its strength and overcome its weakness.

\subsubsection{Strength of Yu'Xin'Ou Railway}

\subsubsection{Advantages of industrial clusters}

Chongqing is the economic center of the upper reaches of the Yangtze River, it's also our country's major modern manufacturing base and high-tech industrial base, there are a large number of manufacturing enterprises. This industrial clusters promote a frequent exchanges of domestic and international cargo, therefore Yu'Xin'Ou Railway has sufficient supplies.

Yu'Xin'Ou Railway originated from the Europe's needs for Chongqing's electronic products. In 2014, one in every 3 computers in the world was produced in Chongqing, 100\% orders of Acer, $90 \%$ orders of Toshiba, $80 \%$ orders of Asus and $60 \%$ orders of HP were in Chongqing. Chongqing becoming the world's largest notebook computer production base, there are around $60 \%$ of cargo which are the electronic products, it is the most important and stable source of the cargo.Chongqing has not only the Asia's largest laptop production base, but also it has its local brand in automobile and auto parts. Thanks to low price and high quality, these auto products are popular in Europe market.

\subsubsection{Advantages of geography}

Chongqing is seated between the well-developed east region and the rich-resources west region, Economic Belt and the Yangtze River Economic Belt. As the end of Yangtze River Economic Belt, it echoes back with Shanghai (the head of Yangtze River Economic Belt). Thanks to its geographical advantage, Chongqing becomes an important integrated traffic hub city.

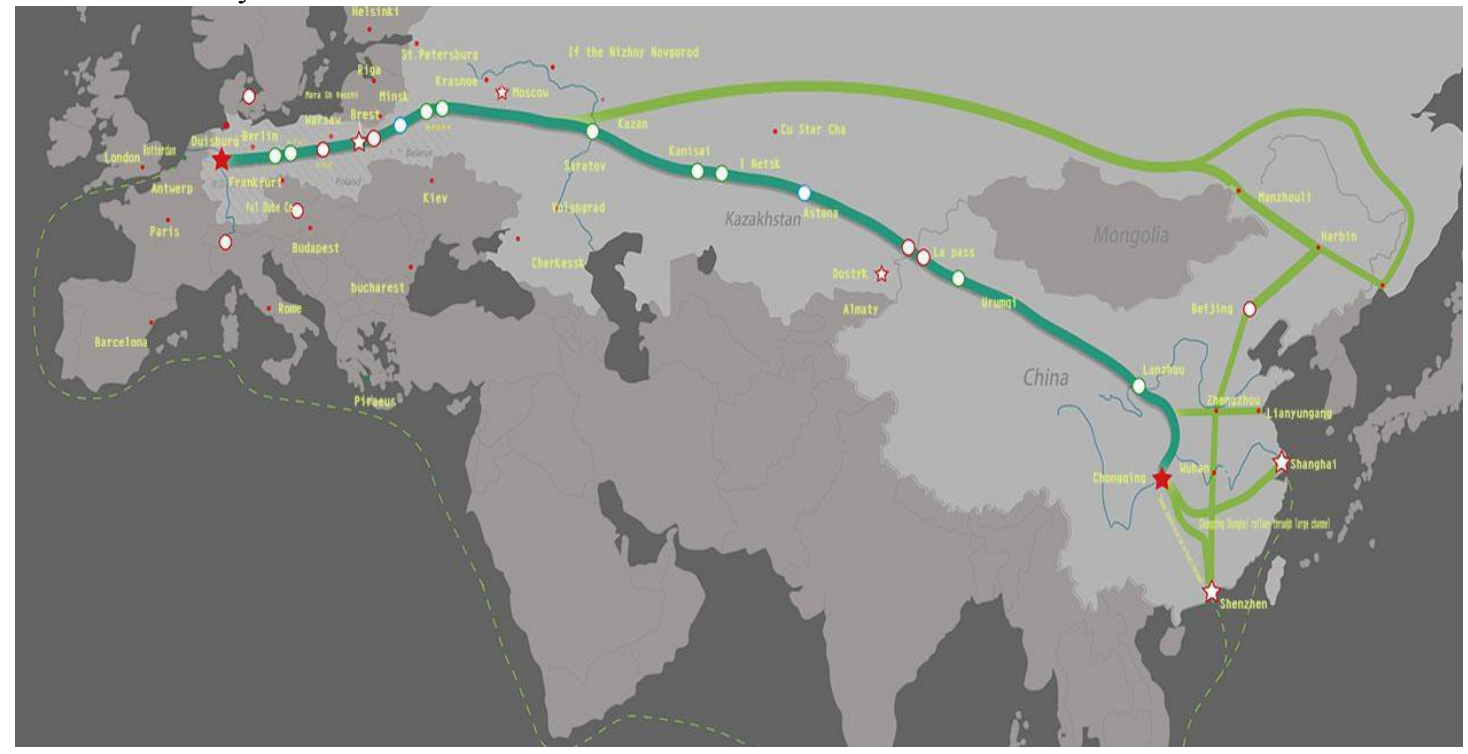

Figure 1. Yuxinou International Railway Logistics Channel

\subsubsection{Advantages of price and period}

The transport period of the whole line which is about 13-15 days is shorter nearly 30 to 40 days than sea transport. The price is about one fifth/sixth of air transport and it has declined year by year. Even was compared with other ChinaEurope Railway, it has competitive advantage. This period and price are very competitive in the international market which changes quickly.

\subsubsection{Advantages of customs and transport mode}


After customs inspection in Chongqing, along the way there is no repeat national customs clearance inspection, it implements in the general the "one declaration, one application, one clearance". Yu'Xin'Ou Railway achieve a " $1+\mathrm{N}$ " mode of distribution operation. " 1 " is the Chongqing to Duisburg main line. "N" is the countries which is along the line as assembly points or distribution point according to customer needs. Now it also offered multiform service:public trains service;international railway transport service;customized multimodal transport logistics services; consolidation cargo service and China; Europe trailer service.

\subsubsection{Weaknesses of Yu'Xin'Ou Railway}

\subsubsection{Coordination difficult with 6 countries}

Yu'Xin'Ou Railway passes a number of countries, because the different countries have different economy developments, their railway construction and maintenance, operation and management and new technology update are different. Such as the standard gauge of China's railway is different from which of other country's railway, Yu'Xin'Ou Railway needs to change pathway in transit, that delays the transport period.

\subsubsection{Lack of stable supply return}

Currently, the organization of return supply is more difficulty than toward supply. China is an export-country, these years China is always at trade surplus' situation. It means that China's capacity depends on the international market. So in order to enhance the autonomy of Chinese economy, the exploitation of return supply, the augment of import and the stimulation of domestic demand are important.

\section{Brief suggestion of reform of Chongqing's private universities under the background of Yu'Xin'Ou Railway}

"One belt, one road" is an outcome of Chinese economy situation and the Eurasian economy situation, Yu'Xin'Ou Railway as an international logistics channel, plays a good leading role. So as Chonqing's private universities, the education system should also advance with the times, meet the demand of Yu'Xin'Ou Railway (渝新欧), provide talents and balance the problem of employment. There are two brief suggestions about the reform of Chongqing's private universities aim at the strength and weakness of Yu'Xin'Ou Railway (渝新欧).

\subsection{Expand cooperation between schools and enterprises in the area of Yu'Xin'Ou Railway}

Based on the advantages of industrial clusters and geography of Yu'Xin'Ou Railway, the private universities can use their own advantage of enterprise model, expand the cooperation with the foreign company,helping with the development of "One Belt and One Road".

One hand, the local students could use the geography resource to provide more effective service. One other hand,it can provide more internship even work opportunities for the students. It can not only export cargo but also export talent form Chongqing to Foreign countries. For the excellent students, the cooperation will optimize their career development. Nowadays, most private universities are application-oriented university, its purpose is to cultivate the technical talent.So the cooperation between schools and enterprises in the area of Yu'Xin'Ou Railway is consistent with this purpose.

\subsection{Expand cooperation with foreign school in the area of Yu'Xin'Ou Railway}

Based on the the coordination difficult with foreign countries, the private universities could expand the cooperation with the foreign school,helping with the development of " One Belt and One Road". As different area,there are many differences of regulation and culture which will obstruct the development of "One Belt and One Road".

According the cooperation with foreign school, The private universities can provide the opportunities of talent exchange. First step,on the line of the Yu'Xin'Ou Railway,Chongqing students can study at foreign universities and foreign students can study at Chongqing's universities,improve communication and learn form each other. Second step, Chongqing's professors can work at foreign universities and foreign professors can work at Chongqing's universities, 
improve foreign language level to boost the development of Yu'Xin'Ou Railway. From the reform of education of private universities, base on the "One Belt and One Road", that will create a academic exchange "Railway", narrow cultural difference.In the future,the Yu'Xin'Ou Railway could transport both goods and passengers.

\section{Conclusion}

At present, "One belt, one road" always meet with many challenges, university is a place which cultivates talents for the future,it plays an important role during the development of "One Belt and One Road". The amount of private universities of Chongqing attained the $40 \%$ of the totality, especially most private universities aim at cultivate technical talents. Meanwhile technical talent is what Yu'Xin'Ou Railway needs,so the reform of private universities at Chongqing should follow the changes and cultivate the technical talent who adapt to the requirements of the times, that will attain the win-win situation.

\section{References}

1. Ma Bin. (2018) The development, problems and responses of the China-Europe train, China International Studies, No. 6, 72-86.

2. Ren Shiwei. (2017) The Strategic transformation and development of private universities under the background

3. of "One Belt and One Road",Contemporary Education Research and Teaching Practice,(12):129.

4. Zhang Hong. (2015) Chongqing Mayor Huang Qifan: "Belt and Road" will enhance Chongqing's opening space, China today

5. http://www.chinatoday.com.cn/chinese/sz/dskzg/201506/t20150615_800034155.html

6. Xia Wenhui,Geng jin,Song Han(2014) Analysis and strategy of SWOT of Yu'Xin'Ou Railway[J].Logistics technology,2014,33(01):1-3+15.

7. Zhao Qingsong. The characteristics, problems and strategies of China-Europe Railway-based on Yu'Xin'Ou Railway[J].Practice in Foreign Economic Relations and Trade,2015(03):33-35. 